\title{
LOS DIEZ MANDAMIENTOS DEL INTRAPRENEUR
}

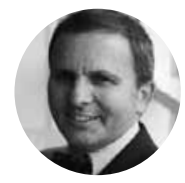

\author{
JACKZILBERMAN F.* \\ - Profesor de Planificación Estratégica y Modelos de Negocio \\ Área Académica de Administración \\ Facultad de Negocios, UPC
}

Kling y Shultz, destacados economistas americanos, inician su libro Invisible Wealth, publicado en 2009 , con una autocrítica, afirmando que sus colegas no han sabido explicar aún cómo las fuerzas de la creatividad, de la innovación y de las nuevas tecnologías impulsan el crecimiento económico. ${ }^{1}$

En nuestra II Conferencia Internacional de Global Management, denominada "Decision-Making in a Global Economy: Between Entrepreneurship and Institutional Maturity", reflexionamos sobre cómo los conceptos de "intrapreneurship", "idea greenhousing" y "open innovation" se utilizan y pueden ayudar a reencender la llama del emprendimiento de los socios fundadores en las corporaciones.

Hace algunas semanas pusimos en marcha a Shift, una iniciativa pionera en nuestro país que forma sinergias entre instituciones públicas, privadas y académicas con la misión de impulsar el desarrollo y la diversificación productiva del sector empresarial, fomentando que la innovación y el intraemprendimiento sean parte de la cultura y la visión estratégica de las organizaciones.

Cuando nos referimos a intraemprendimiento nos equivocamos al pensar que es un término novedoso como producto del acelerado avance de las tecnologías y las comunicaciones. Gifford Pinchott III, consultor y emprendedor americano, lo definió en 1984 como "intrapreneuring" y lo asoció a los soñadores que ejecutan, que asumen riesgos y responsabilidades para generar innovaciones dentro de una organización. ${ }^{2}$ Identificó finalmente el problema de las grandes corporaciones para poder planificar y controlar la incertidumbre y la limitada predictibilidad inherentes a la innovación.

Por otro lado, el sistema por sí mismo no funcionaría sin una cultura del cumplimiento de las normas tributarias, un tema por el que todo contador debe velar. Es cierto que algunos procesos internos se ven entorpecidos por la aplicación de nuevas normas, pero su cumplimiento no está en discusión.

Un buen sistema debe tener la capacidad de obtener información según los requerimientos de la administración tributaria. El uso de Internet para el pago de los impuestos y la implementación progresiva de las facturas electrónicas, viene haciendo posible que la información que la administración tributaria maneja esté siempre actualizada.
Aprovechando las ventajas de la tecnología, el contador debe informar a las áreas relacionadas con los procesos contables acerca de los plazos de cierre de cada subsistema y de los requisitos que deben cumplir los documentos ingresados. La información, luego de ser analizada, será comunicada por medio de los Estados Financieros. El contador se apoyará en los sistemas también para la obtención de otros reportes y para establecer mecanismos de control que garanticen que los bienes de la empresa estén bien resguardados. Sin duda, gracias al aporte de los sistemas, la contabilidad se ha convertido en una herramienta clave para la toma de decisiones de los directivos de las empresas.

\section{LOS INTRAEMPRENDEDORES SE DIFERENCIAN CLARAMENTE DENTRO DE UNA ORGANIZACIÓN POR SU AUDACIA Y SU FLEXIBILIDAD PARA PENSAR FUERA DE LA CAJA.}

\begin{abstract}
Los intraemprendedores se diferencian claramente dentro de una organización por su audacia y su flexibilidad para pensar fuera de la caja y por tomar decisiones rápidas en entornos inciertos. Son aquellos líderes y comunicadores capaces de identificar oportunidades y transformarlas en innovaciones de elevado potencial, trabajando en equipos de alto rendimiento y con recursos de la organización, bajo un entorno adecuado que impulse la creatividad.
\end{abstract}

Pinchott describe magistralmente la personalidad del "intrapreneur" para superar la resistencia al cambio dentro de las organizaciones, a través de "diez mandamientos", entre los cuales los siguientes deben resaltarse: i) Llega al trabajo cada día sabiendo que puedes ser despedido; ii) encuentra la mejor gente siguiendo tu intuición, para trabajar en equipo; iii) trabaja en silencio lo máximo posible, el sistema inmunológico de alerta corporativa se activa con la noticia; iv) realiza cualquier tarea que contribuya con el éxito del proyecto sin importar la descripción de tu puesto; v) no apuestes por una iniciativa, a menos que participes activamente en ella. 
El Foro Económico Mundial parece responderle a Kling y a Shultz con el último Reporte de Competitividad Global, en el cual concluye que la innovación tecnológica no solamente es fundamental para una economía competitiva y en crecimiento como consecuencia de los incrementos relevantes en la productividad y en el valor agregado de las empresas, sino también por el desarrollo del talento asociado, seguramente intraemprendedor, y por el entorno colaborativo eficaz entre los sectores público y privado para lograr un desarrollo económico sostenible e incluyente.

\section{TENEMOS, POR TANTO, UN DESAFÍO MAYÚSCULO PARA FORMAR TALENTO, DESARROLLAR NUEVOS MODELOS PRODUCTIVOS Y DE SERVICIOS Y PODER SOSTENER EL CRECIMIENTO.}

En 2030, seremos más de 36 millones de peruanos con una población mundial cercana a los 8,500 millones. Tenemos, por tanto, un desafío mayúsculo para formar talento, desarrollar nuevos modelos productivos y de servicios y poder sostener el crecimiento. En la UPC, por ejemplo, estamos muy ilusionados en ser parte activa de este esfuerzo colectivo y colaborativo; de potenciar el ecosistema de emprendimiento e innovación local; y aplicar las mejores prácticas de modelos exitosos como Finlandia, Suiza, Israel, Estados Unidos, Singapur y Alemania.

Nos queda mucho camino por recorrer. En la medida en que construyamos esta posibilidad trabajando en equipo, reconociendo el valor de la innovación y del espíritu intraemprendedor y sembremos las bases de una verdadera institucionalidad, podremos volver muy pronto a los niveles de crecimiento e inversión que necesitamos para otorgar igualdad de oportunidades a la población y terminar o reducir la pobreza en nuestro querido Perú.

1. Kling, A., \& Shultz, N. (2009). Invisible Wealth: The hidden story of how markets work.

2. Pinchot, G. (1984). Who is Intrapreneur? En Intrapreneuring Why You Don't Have to Leave the Corporation to Become an Entrepreneur. 